\section{Cureus}

\title{
Postoperative Cyst Associated with Bone Morphogenetic Protein Use in Posterior and Transforaminal Lumbar Interbody Fusion Managed Conservatively: Report of Two Cases
}

\author{
Eli M. Baron ${ }^{1}$, Diana M. Mejía ${ }^{2}$, Doniel Drazin ${ }^{3}$, Neel Anand ${ }^{4}$ \\ 1. Neurosurgery, Cedars-Sinai Medical Center 2. Department of Physical Medicine and Rehabilitation, University of \\ Miami - Jackson Memorial Hospital 3. Department of Neurosurgery, Cedars-Sinai Medical Center 4. Surgery, \\ Cedars-Sinai Medical Center
}

$\square$ Corresponding author: Eli M. Baron, ebaron@temple.edu Disclosures can be found in Additional Information at the end of the article

\section{Abstract}

Bone morphogenetic protein use in spinal surgery for off-label indications continues to remain popular. One area where its use has known associated radicular complications is posterior or transforaminal lumbar interbody fusion. These complications include radiculitis, cyst development, and heterotopic ossification, amongst others. Typically, cyst development has been treated surgically. We present two cases of bone morphogenetic protein-related cysts treated medically and thus, present medical treatment as an alternative treatment option.

Categories: Neurosurgery, Orthopedics

Keywords: bone morphogenetic protein, spinal fusion, off-label

\section{Introduction}

Bone morphogenetic protein (BMP) was initially identified by Urist in the early 1970s [1-3]. Since then, BMPs have been used for numerous clinical indications where new bone formation and fusion is required including craniofacial surgery, long bone fracture repair, and spinal surgery, among others [4-7].

Recombinant bone morphogenetic protein 2 (rhBMP-2), one of the transforming growth factors- $\beta$ group, was approved by the FDA in 2002 for use in skeletally mature patients, in cages in anterior lumbar interbody fusion (ALIF) [8]. It promotes osteogenesis, helping mesenchymal cells differentiate into osteoblasts, and affects bone resorption [9-11]. The first human clinical trial reporting the success of rhBMP-2 in ALIF was Boden et al., in 2000 [12]. Since then, rhBMP-2 has become widely used as an alternative to autogenous bone grafting in lumbar anterior interbody fusion [13-15].

In addition to its FDA-approved use in the lumbar spine for ALIF (within a cage), its off-label use in the spine increased significantly in the last decade. Partially as a result of commercialization and high reported fusion rates, the use of rhBMP-2 in all fusions increased between 2002 and 2006 from $0.69 \%$ to $24.89 \%$ [16]. Using the Nationwide Inpatient Sample, Ong et al. noted the predominant use of spinal rhBMP-2 between 2003 and 2007 to be primary posterior lumbar interbody fusion (PLIF) or transforaminal lumbar interbody fusion (TLIF) (30.0\%), followed by primary posterolateral spine fusion (20.4\%) and primary ALIF (16.6\%) [17]. Thus, off-label use of rhBMP-2 far exceeded its on-label use in ALIF cages during this time period in the United States.

Initial studies showed bone formation using BMP-2 to occur with equal or greater efficacy when compared with iliac crest autograft [18-19]. As increased use of the protein occurred, several authors reported significant morbidity related to its use [20-25]. RhBMP-2 has been related to numerous physiologic cascades responsible for both the benefits and the morbidity associated with its application. The protein induces cell proliferation, differentiation, and apoptosis, which are key elements in the osteogenesis process [26]. Conversely, it also promotes the expression of a number of inflammatory

\section{How to cite this article}

Baron E M, Mejía D M, Drazin D, et al. (February 07, 2016) Postoperative Cyst Associated with Bone 


\section{Cureus}

agents including interleukin-1a, 1b, 6, as well as tumor necrosis factor-a, which may be responsible for many of its side effects $[11,27]$. In addition to inflammatory radiculitis, epidural heterotopic bone formation anterior to or in the spinal canal is also responsible for some of the complications related to rhBMP-2 in the disc space. Uncontrolled bone growth and cyst formation have been found compressing adjacent neural structures causing postoperative radiculopathy, leg pain, and motor and/or sensory deficits [20, 28-31]. These cases have been treated most commonly with surgical intervention aimed to decompress the affected neural structure.

We report two patients who developed a posterior cyst after the off-label use of rhBMP-2 in PLIF and TLIF surgery. Both patients presented with radiculopathy a few weeks to months after the surgery. The diagnosis was confirmed through postoperative MRIs that showed nerve root compression or presence of a postoperative cyst. These patients were treated conservatively, and no second surgical intervention was performed. After at least one year at follow-up, these patients showed complete fusion with calcification of the cyst walls and stabilization or resolution of the symptoms. These cases support a noninterventional treatment option for postoperative cyst formation after rhBMP-2 use during TLIF/PLIF.

\section{Case Presentation}

\section{Case 1}

A 48-year-old male presented with a history of two years of severe, worsening, right buttock and right posterior thigh pain. Six weeks prior to the visit and associated with the pain, the patient started to have right foot numbness in the second and third toe, which in the 4-5 days prior to the visit had extended to the bottom of the right foot compromising his walking. He also presented with occasional right calf numbness and spasms. Walking and standing exacerbated the lower extremity pain, while lying down in a fetal position provided some relief. The symptoms did not respond to conservative treatments which included analgesics and a lumbar support brace. The physical exam was normal except for numbness in the dorsum of the right foot and diminished right ankle reflex. Preop radiographs showed a Grade I L5-S1 lytic spondylolisthesis and MRI showed an L5-S1 disk herniation with clear protrusion into the spinal canal (Figures 1A, 1B).

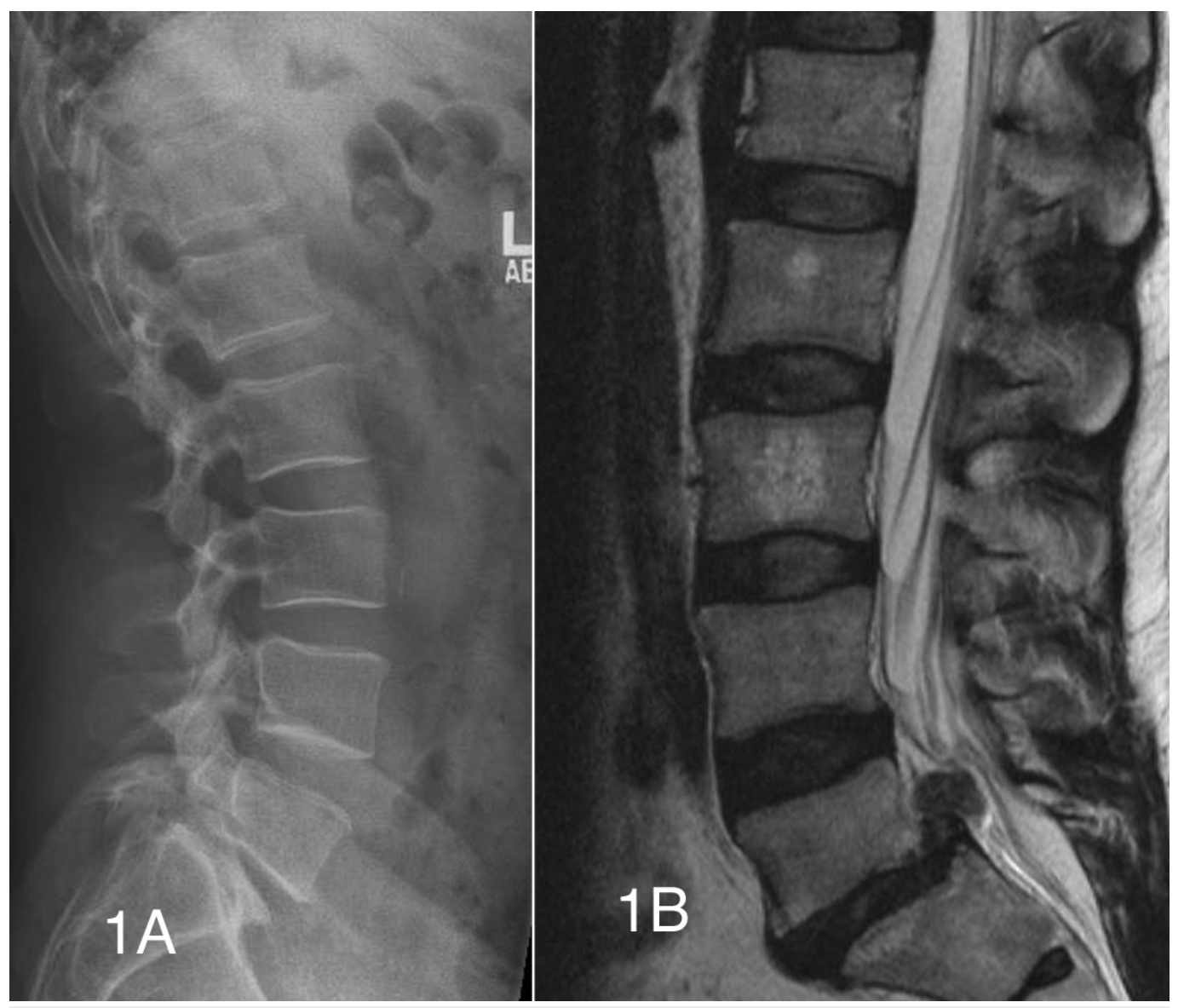




\section{Cureus}

\section{FIGURE 1: Preoperative lateral radiograph and t2 weighted sagittal}

MRI

(Figure 1A) Lateral lumbar radiograph showing a grade I L5-S1 spondylolisthesis. (Figure 1B) T2 sagittal MRI reveals a large L5-S1 disc herniation in the setting of grade I L5-S1 spondylolisthesis.

The patient underwent L5-S1 radical discectomy and posterior lumbar interbody fusion (PLIF) with local bone autograft Grafton putty demineralized bone matrix and $3 \mathrm{mg}$ of RhBMP-2 divided and placed into two polyetheretherketone (PEEK) spacers.

After the surgery, the patient reported a significant decrease in the right lower extremity pain; however, the right foot numbness still persisted. One and a half weeks after the surgery, the patient started experiencing radiating aching pain through the right posterior thigh that stopped around the posterior right knee. He also had worsening hypersensitivity in his second and third right toes and tightness sensation from his right thigh all the way down the ipsilateral foot. Doppler ultrasound ruled out a possible deep venous thrombosis. X-rays of the lumbar spine demonstrated instrumentation to be intact with no lucency at the screw-bone interface (Figures $2 A, 2 B$ ).

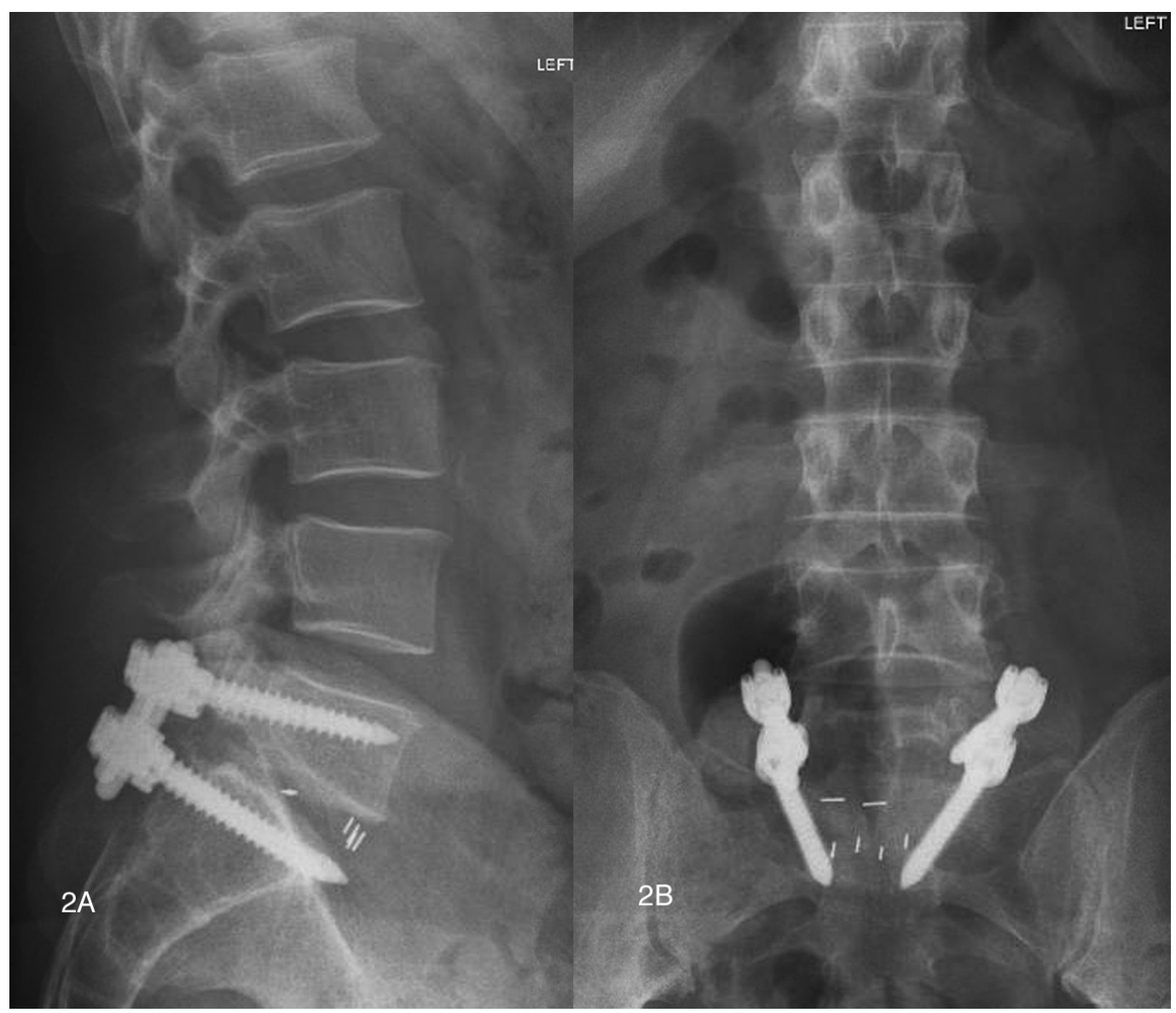

\section{FIGURE 2: Postoperative lateral and AP radiographs}

(Figures 2A, 2A) Lateral and anteroposterior radiographs demonstrating appropriate PLIF graft and pedicle screw instrumentation placement.

An EMG/NCV study of the lower extremities two months after the procedure suggested reinnervation of the right S1 nerve, but also showed a degree of acute denervation in his right L5 area. An MRI of the lumbar spine revealed a right-side fluid collection at L5-S1, visualized within the right neural foramen 


\section{Cureus}

and lateral recess (Figures $3 A, 3 B$ ).

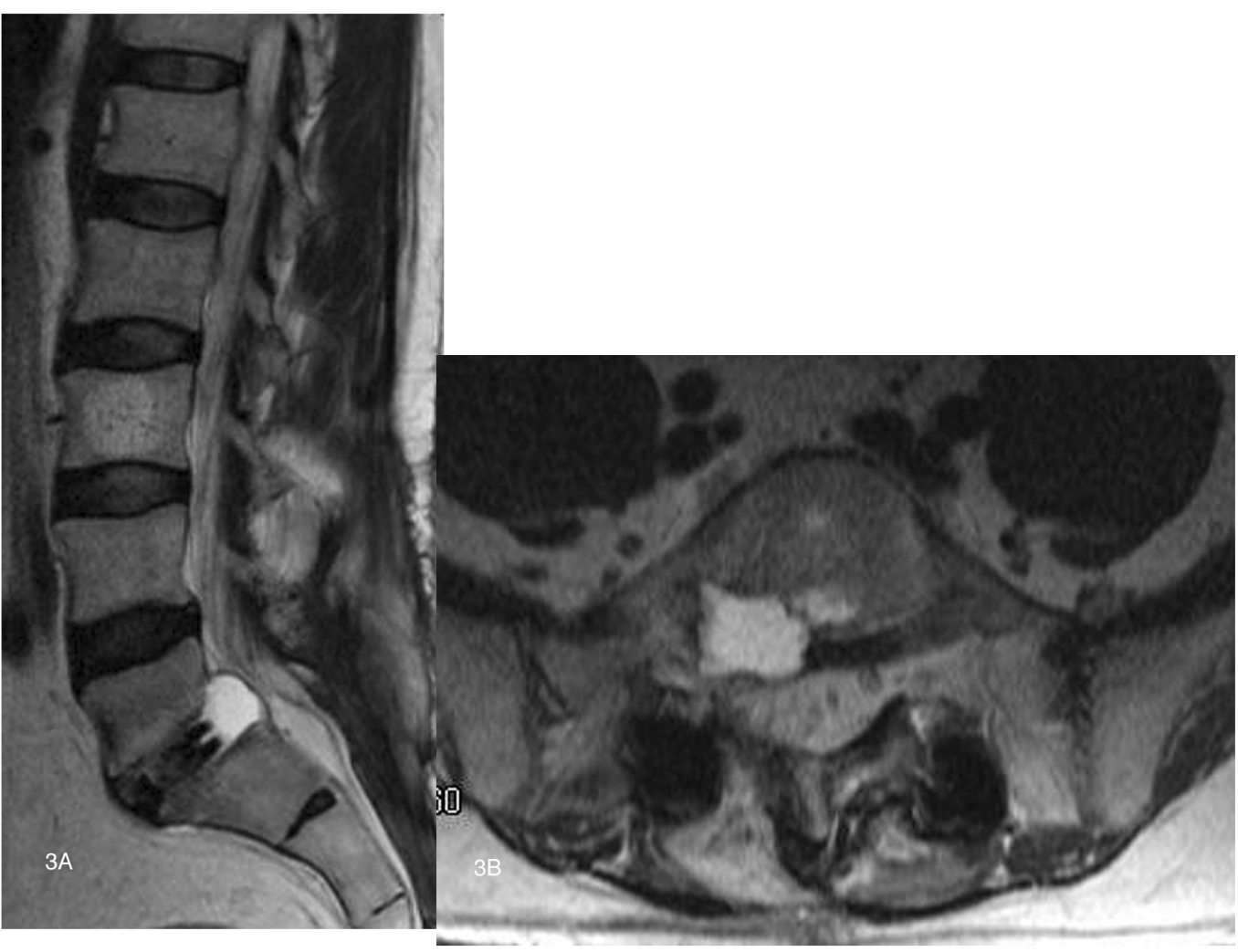

FIGURE 3: Postoperative T2 weighted sagittal and axial MRI imaging showing cyst

(Figure 3A) T2 sagittal MRI. (Figure 3B) T2 axial MRI demonstrating hyperintense cyst emanating from the disc space and ventrally compressing the right L5-S1 lateral recess.

Surgical decompression was offered to the patient; however he decided to defer the intervention and requested to be treated conservatively. The patient was treated with Neurontin 200mg twice daily and Mobic $7.5 \mathrm{mg}$ twice daily, which improved his symptoms.

Fifteen months after the surgery, the patient had residual but stable right-side calf and foot numbness. However, the patient increased his activities and was satisfied with the results of the surgery. A one-year CT scan postop study showed a robust interbody L5-S1 level and light calcification along the borders of where the cyst was observed (Figures $4 A, 4 B$ ). 


\section{Cureus}
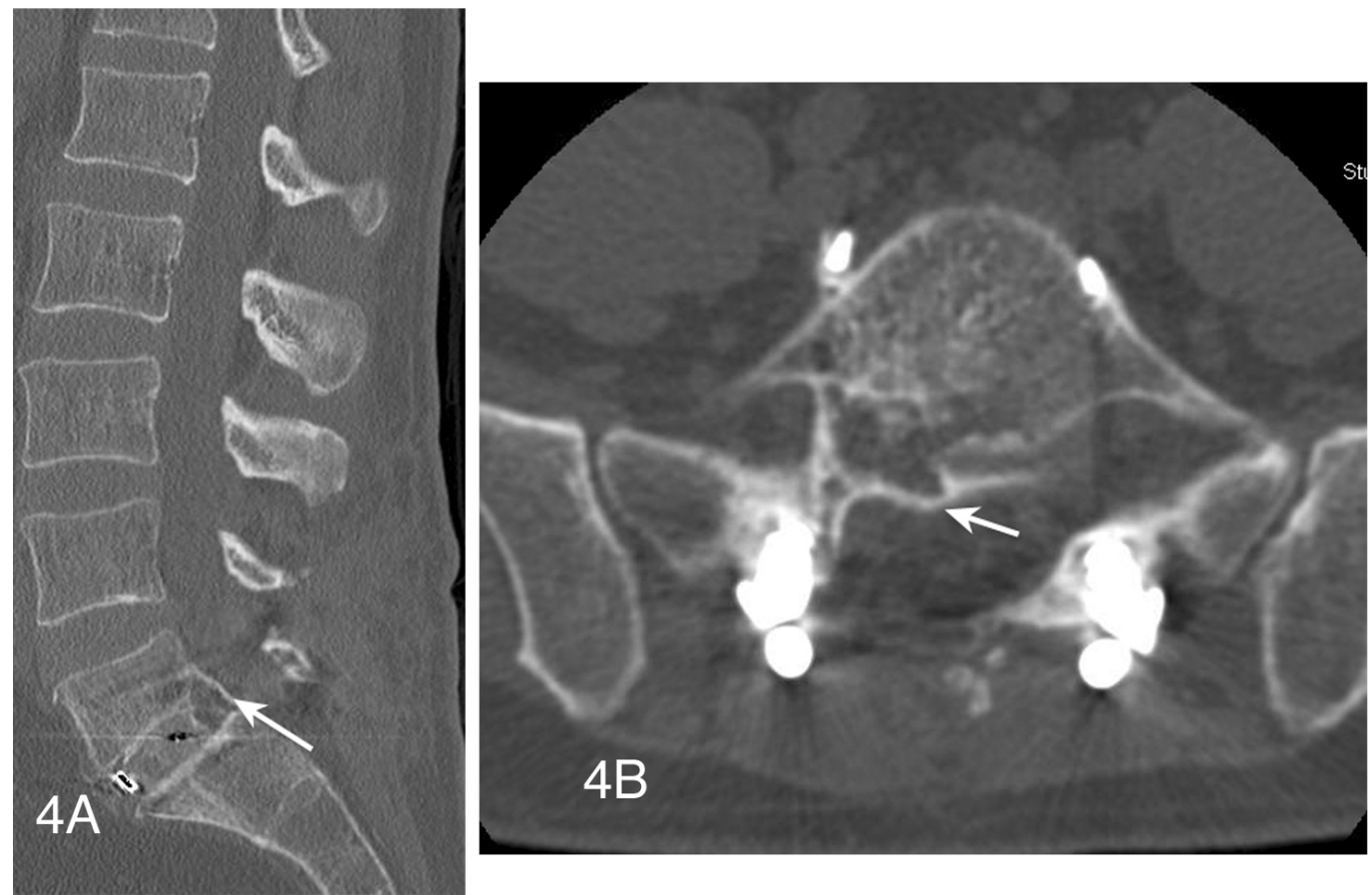

\section{FIGURE 4: Postoperative sagittal and axial CT images showing calcification along former cyst wall}

(Figure 4A) Sagittal CT reconstruction image demonstrating a solid fusion across the disc space with calcification posteriorly along the previously seen cyst wall (arrow). (Figure 4B) This also visualized on an axial CT image (arrow) and appears to extend into an area of osteolysis along the posterior inferior vertebrae.

\section{Case 2}

A 29-year-old female with a history of left-sided L5-S1 microdiscectomy from several years previous developed a right-sided L5-S1 disk herniation. She presented with excruciating intractable back, buttock, and leg pain. There was evidence of a retrolisthesis at L5-S1, in addition to a collapsed disk at this level. The patient was also noted to have mild stenosis at L4-L5. After failing to improve from nine months of conservative care, surgery was offered.

The patient underwent right-sided L5-S1 transforaminal lumbar interbody fusion in addition to L5-S1 laminectomy and a decompressive laminotomy at L4-L5. Bone morphogenetic protein was used in the intervertebral cage and for a contralateral posterolateral facet fusion. An oblique PLIF cage was inserted via TLIF technique containing $2.1 \mathrm{mg}$ of rhBMP-2 (Figures $5 A, 5 B$ ). 


\section{Cureus}

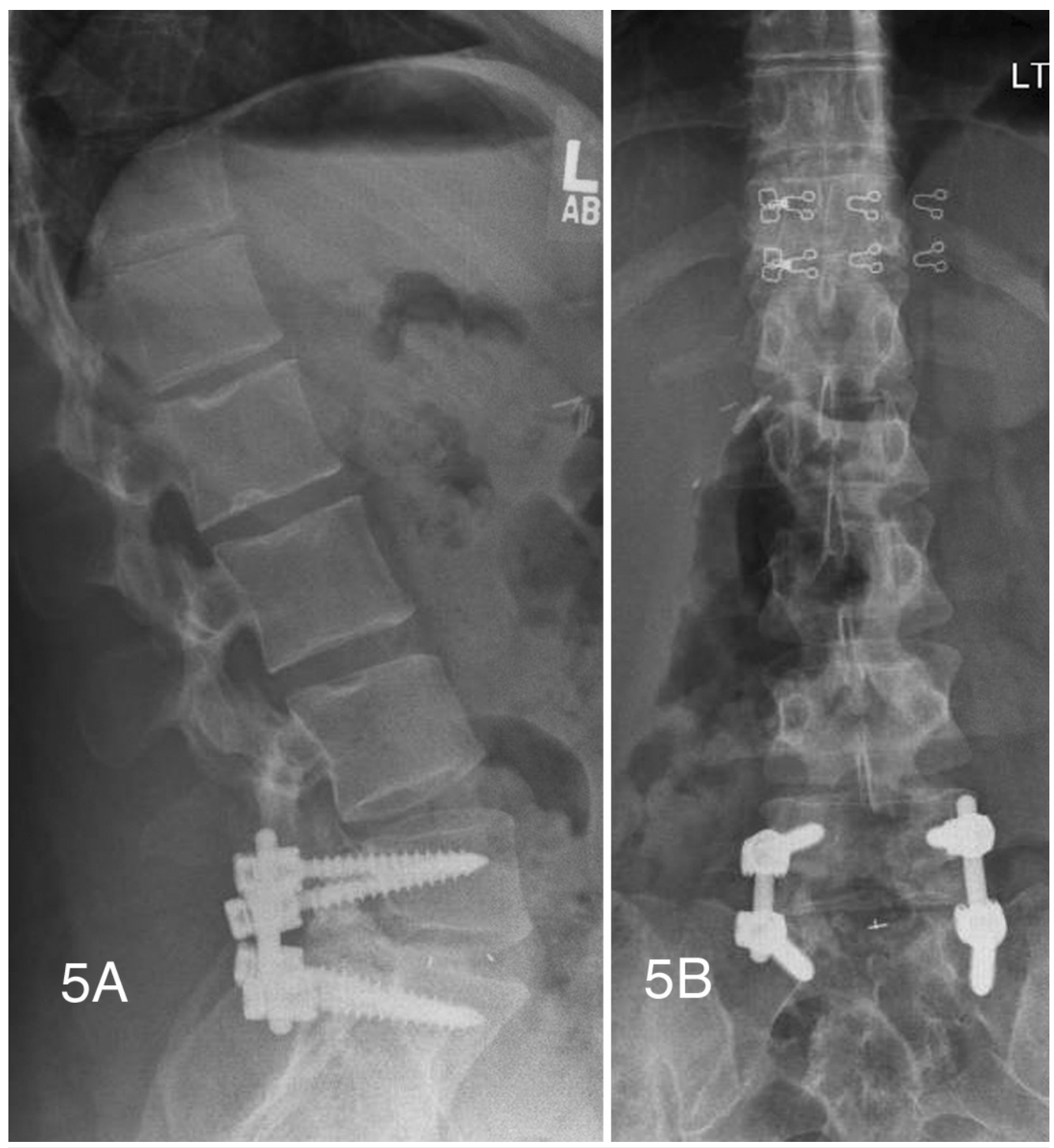

\section{FIGURE 5: Postoperative lateral and AP radiographs}

(Figures 5A, 5B) Lateral and AP radiographs showing proper pedicle screw and oblique PLIF cage placement using TLIF technique.

Several months after surgery, the patient was noted to have new onset buttock pain and right leg pain. T2 MRI of the lumbar spine revealed a hyperintense fluid collection extending just posterior to the disc space on the right side. On sagittal imaging this could be seen to be displacing the right S1 nerve root posteriorly (Figures 6A, 6B). 


\section{Cureus}

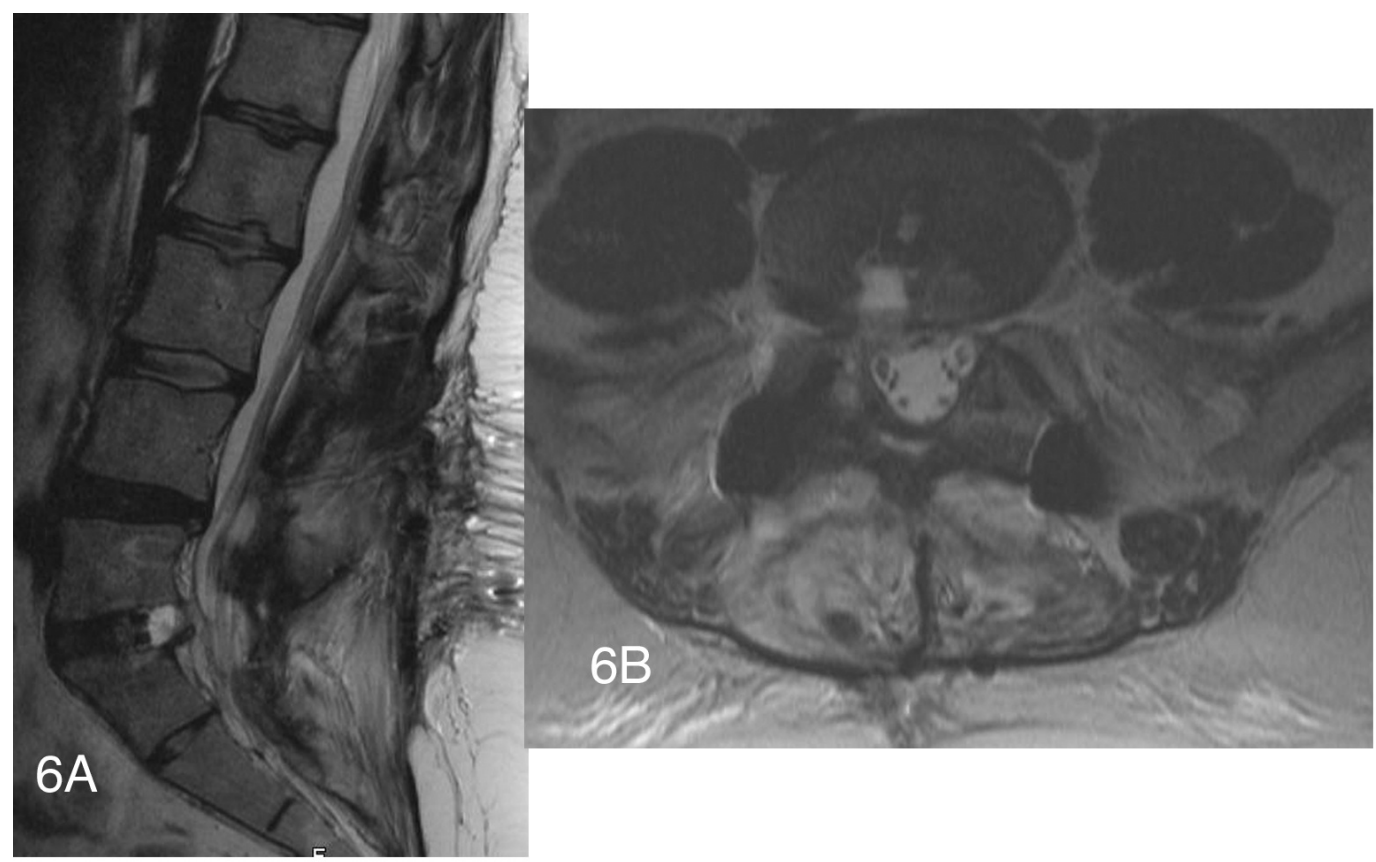

FIGURE 6: Postoperative T2 weighted sagittal and axial MRI imaging showing cyst

T2 weighted sagittal and axial MRI imaging demonstrating right sided cystic flud collection in the disc space.

The right S1 nerve root appears to be displaced posteriorly on the sagittal image.

Inflammatory markers, including ESR and CRP, were obtained and found to be within normal limits. Given this, a right L5-S1 transforaminal epidural steroid injection was performed with good relief of symptoms; over several months her leg pain resolved. Follow-up CT scan at one-year post-op displayed a solid interbody fusion and solid fusion of the left L5-S1 facet joint (Figures 7A, 7B).

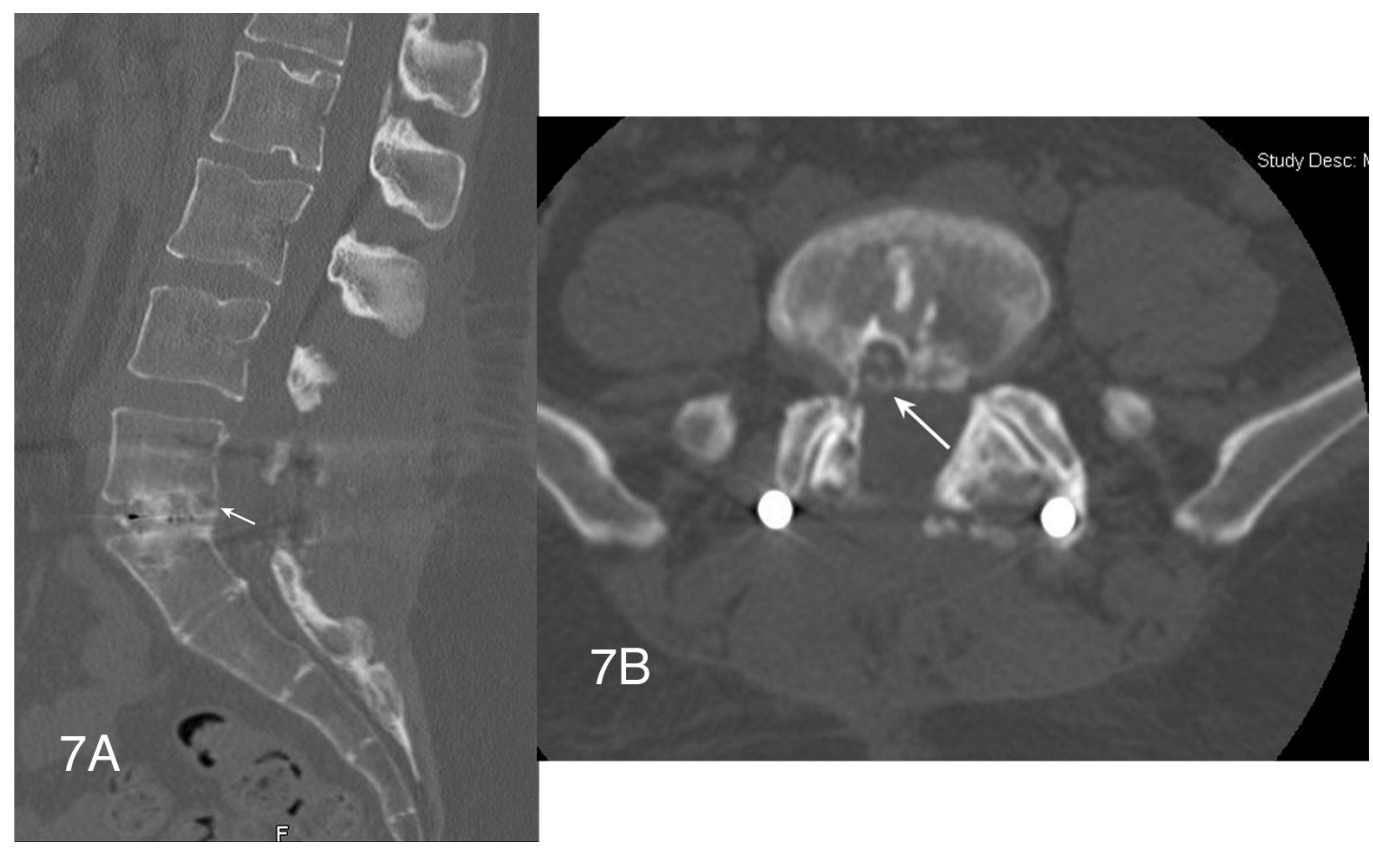

FIGURE 7: Sagittal and axial postoperative CT images showing calcification along previously noted cyst wall 


\section{Discussion}

In the past decade, the use of rhBMP-2 has become increasingly common to promote lumbar interbody fusion. After the FDA approved the use of rhBMP-2 in the LT cage for ALIF, off-label use of BMP increased significantly, specifically in TLIF/PLIF and posterolateral fusion [16-17]. Significant radicular complications, however, have been reported associated with its use, both in the early and late perioperative period $[20,22,24,30,32-36]$.

Radiculopathy after TLIF/PLIF has been reported at 0-18\% in studies where BMP was used [21]. In a study conducted by Rihn et al., $14 \%$ of the patients presented with ipsilateral, postoperative leg pain in a dermatomal distribution after TLIF with BMP (3\% without BMP) [24]. Conversely, only $16 \%$ of the cases were related to heterotopic bone formation. Causes of radiculopathy can be divided into two categories: compressive and non-compressive. Stenosis, heterotopic ossification (HO), fluid collection, and scars are examples of causes of compressive radicular pain. Non-compressive radiculopathy causes include inflammation of the nerve root (usually without imaging findings and seen most commonly) and infection [26]. Mindea et al., reported that $11 \%$ of the patients who underwent TLIF with rhBMP-2 had radicular symptoms with no abnormality on postoperative CT scans [34]. In a retrospective study of 199 patients who underwent single level TLIF, 86 patients received rhBMP-2 [24]. Of these, a hydrogel sealant (Duraseal; Confluent Surgical Inc., Waltham, MA, USA) was used in 37 patients. The Duraseal group showed a $5.4 \%$ incidence of postoperative radicular symptoms versus $20.4 \%$ when the hydrogel sealant was not used (with rhBMP-2). Duraseal is believed to provide a protective layer for nerve roots and the dural, effectively isolating them from the rhBMP-2. Nevertheless, concerns about postoperative swelling associated with use of Duraseal, and subsequent radicular or thecal sac compression, have been raised which may temper enthusiasm about its use in this setting [34, 37]. Others have considered the use of fibrin glue for this purpose [38].

Rates of HO after TLIF/PLIF where rhBMP-2 has been used also vary widely. Haid et al., in a prospective, randomized, non-blinded, two-year study at 14 investigational sites comparing PLIF with rhBMP-2 to autogenous iliac bone graft reported on $\mathrm{HO}$ as noted on $\mathrm{CT}$, and found $75 \%$ of the patients who underwent PLIF with rhBMP-2 had HO compared to $12.9 \%$ of cases in subjects where BMP was not used [39]. In an observational study with prospective CT analysis, Joseph and Rampersaud noted an incidence of epidural bone formation of $20.8 \%$ in patients undergoing PLIF or TLIF with the use of rhBMP-2 compared with an incidence of $8.3 \%$ in patients undergoing PLIF/TLIF with local autogenous bone graft [29]. Rates of HO reported in numerous series vary from $0-75 \%$, with many asymptomatic cases [21]. The mechanism of this HO formation after TLIF is not fully understood but may involve a chondrocyte differentiation pathway [40].

Cyst formation is a less commonly reported complication related to the off-label use of rhBMP-2. Just a few case reports in the literature discuss the presence of cyst formation associated with radicular pain. Choudhry et al., described the presence of a symptomatic inflammatory cyst presenting six weeks after TLIF [20] wherein $8.4 \mathrm{mg}$ of rhBMP-2 was used inside a PLIF cage inserted using oblique TLIF technique [41]. The authors reported the case of a patient who developed inflammatory fibroblastic cyst formation around the rhBMP-2 sponge, which compressed the L4 nerve root at its axilla. Decompression and excision of the cyst were performed in a second surgery eight weeks after the index procedure with resolution of patient's symptoms. Histopathologic specimen analysis confirmed the presence of a rhBMP2 sponge material surrounded by mild, chronic inflammation where hemosiderin-laden macrophages with foci of calcifications were noted.

Than et al., described a case of back and right lower extremity pain 20 months after initially successful L4-L5 fusion for spondylolisthesis [42] wherein $2.1 \mathrm{mg}$ of rhBMP-2 was used in the disc space.

Postoperative MRI showed a right-side cystic mass at L4-L5. Peripheral calcification was demonstrated on CT scan. Surgical resection of the mass was performed in this patient with improvement in his symptoms. Histopathology of the resected tissue revealed the presence of new connective tissue as well as new bone and cartilage formation. 
Mannion et al., reported on 30 patients undergoing 36 spinal levels of TLIF and PLIF with low-dose rhBMP-2 where $1.4 \mathrm{mg}$ was used per level fused [23]. They followed all patients clinically and obtained CT scans six months out from surgery. They note two patients with inflammatory cysts and two patients with HO. Of the two patients with cysts, one had severe symptoms that resolved spontaneously and continues to be followed clinically. The other patient had their cage retropulsed into the disc space; that patient underwent cyst drainage and cage reinsertion with resolution of the patient's radicular symptoms.

Surgical exploration with cyst drainage/resection, the most common treatment for cyst formation after lumbar interbody fusion with rhBMP-2, has been reported to provide immediate symptom relief and thus has been advocated $[20,42]$. Another advantage of re-exploration is the direct visualization of the affected area, which can be especially beneficial in the presence of compressive scar tissue, seroma, or hematoma. The disadvantage, however, is that patients have to undergo another surgical intervention that also carries its own risks and complications including infection, durotomy, and possible neurologic injury. The first author (E.B) had a case where cyst drainage resulted in marked weakness of a patient's dorsiflexors where at surgery there was no visualization of a frank root injury. Post-op MRI showed excellent cyst removal, and CT myelography failed to reveal any abnormalities. A second intervention in the same area also increases the risk of scar tissue formation that can subsequently compress the surrounding neural structures as well as irritation of the nerve root.

Both patients in this case report exhibited total recovery from their initial symptoms after their single level TLIF or PLIF. RhBMP-2 was used in both cases with solid interbody fusion in both patients. Several weeks after their fusion procedures, however, the patients' radicular pain reappeared. In both cases, MRI of the lumbar spine confirmed adequate position of the cages and the hardware material. Instead, cyst formation was observed at the level of the fusion. Compression of the adjacent nerve roots or local inflammation was found to be the cause of their postoperative symptoms. Treatment options were discussed with the patients, and they both declined a possible surgical excision of the cyst. Both patients received conservative treatment which included oral analgesics, and an epidural injection in one of the cases. Partial relief of the symptoms was observed in both patients. Follow-up images showed the cysts to be stable in size in addition to peripheral calcification observed at the twelve-month follow-up. This finding further supports rhBMP-2 as the cause of these inflammatory cyst formations.

Measures to prevent inflammatory cyst formation as well as HO may be taken in order to avoid some of the morbidity related to the procedure. Using lower doses of rhBMP-2 may achieve successful fusion and avoid some of its inflammatory side effects [23, 43]. Excessive, uncontrolled bleeding could predispose migration of rhBMP-2 to the spinal canal and may itself be a risk factor for $\mathrm{HO}$ [44]. Effective hemostasis theoretically could decrease the incidence of $\mathrm{HO}$ and postop cyst formation. Irrigation of the surgical field after cage insertion with rhBMP-2 may also reduce inflammation in the spinal canal by washing away any unbound rhBMP-2 [34]. Additional investigation on Duraseal and other barriers as a prophylactic measure should aim to determine their safety and efficacy to decrease postoperative radiculopathy related to rhBMP-2 . Finally, rhBMP-2 should be placed in cages as far away from the spinal canal as possible. When performing TLIF, we prefer a C-shaped graft positioned maximally anteriorly with the rhBMP-2 in the cage to minimize the risks of its effect on the canal; additionally, this technique has the benefit of increased lordosis over other TLIF techniques [45].

\section{Conclusions}

Cyst formation related to rhBMP-2 use in PLIF and TLIF has been reported. Cysts may be compressive causing neurologic symptoms. Successful management options include both nonoperative measures and surgical management. An emphasis should be placed on prevention through judicious use of low-dose rhBMP-2, proper cage placement containing the protein, hemostasis, appropriate post cage insertion irrigation, and possibly the use of barrier materials.

\section{Additional Information \\ Disclosures}

Human subjects: All authors have confirmed that this study did not involve human participants or tissue. Conflicts of interest: In compliance with the ICMJE uniform disclosure form, all authors declare the following: Payment/services info: All authors have declared that no financial support was received from any organization for the submitted work. Financial relationships: Eli Baron declare(s) royalties 
from Elsevier. On a textbook. Eli Baron declare(s) royalties from McGraw Hill. Textbook. Neel Anand declare(s) personal fees from Medtronic. Consulting. Neel Anand declare(s) personal fees from Globus Medical. Consulting. Neel Anand declare(s) personal fees from Stryker. Consulting. Neel Anand declare(s) a patent from AtlasSpine. Neel Anand declare(s) a patent from Medtronic. Neel Anand declare(s) a patent from Paradigm Spine. Neel Anand declare(s) a patent from Globus. Neel Anand declare(s) a patent from Nuvasive. Neel Anand declare(s) a patent from Theracell. Other relationships: All authors have declared that there are no other relationships or activities that could appear to have influenced the submitted work.

\section{References}

1. Iwata H, Urist MR: Protein polysaccharide of bone morphogenetic matrix. Clin Orthop Relat Res. 1972, 87:257-274.

2. Urist MR, Iwata H, Strates BS: Bone morphogenetic protein and proteinase in the guinea pig. Clin Orthop Relat Res. 1972, 85:275-290.

3. Urist MR, Strates BS: Bone morphogenetic protein. J Dent Res. 1971, 50:1392-1406. $10.1177 / 00220345710500060601$

4. Sailer HF, Kolb E: Application of purified bone morphogenetic protein (BMP) in cranio-maxillo-facial surgery. BMP in compromised surgical reconstructions using titanium implants. J Craniomaxillofac Surg. 1994, 22:2-11. 10.1016/S1010-5182(05)80289-6

5. Calori GM, Mazza E, Colombo M, Ripamonti C, Tagliabue L: Treatment of long bone non-unions with polytherapy: indications and clinical results. Injury. 2011, 42:587-590. 10.1016/j.injury.2011.03.046

6. Lo KW, Ulery BD, Ashe KM, Laurencin CT: Studies of bone morphogenetic protein-based surgical repair . Adv Drug Deliv Rev. 2012, 64:1277-1291. 10.1016/j.addr.2012.03.014

7. Hsu WK, Nickoli MS, Wang JC, Lieberman JR, An HS, Yoon ST, Youssef JA, Brodke DS, McCullough CM: Improving the Clinical Evidence of Bone Graft Substitute Technology in Lumbar Spine Surgery . Global Spine J. 2012, 2:239-248. 10.1055/s-0032-1315454

8. InFUSE ${ }^{\mathrm{TM}}$ Bone Graft/LT-CAGE ${ }^{\mathrm{TM}}$ Lubar Tapered Fusion Device- P000058 FDA Approval . Accessed: Accessed: July 2015:

http://www.fda.gov/MedicalDevices/ProductsandMedicalProcedures/DeviceApprovalsandClearances/Recen ApprovedDevices/....

9. Giannoudis PV, Kanakaris NK, Einhorn TA: Interaction of bone morphogenetic proteins with cells of the osteoclast lineage: review of the existing evidence. Osteoporos Int. 2007, 18:1565-1581. 10.1007/s00198-007-0441-x

10. Groeneveld EH, Burger EH: Bone morphogenetic proteins in human bone regeneration . Eur J Endocrinol. 2000, 142:9-21. 10.1530/eje.0.1420009

11. Marusic A, Grcevic D, Katavic V, Kovacic N, Lukic IK, Kalajzic I, Lorenzo JA: Role of B lymphocytes in new bone formation. Lab Invest. 2000, 80:1761-1774.

12. Boden SD, Zdeblick TA, Sandhu HS, Heim SE: The use of rhBMP-2 in interbody fusion cages. Definitive evidence of osteoinduction in humans: a preliminary report. Spine. 2000, 25:376-381.

13. Sandhu HS: Anterior lumbar interbody fusion with osteoinductive growth factors . Clin Orthop Relat Res. 2000, Feb:56-60.

14. Burkus JK: Bone morphogenetic proteins in anterior lumbar interbody fusion: old techniques and new technologies. Invited submission from the Joint Section Meeting on Disorders of the Spine and Peripheral Nerves, March 2004. J Neurosurg Spine. 2004, 1:254-260. 10.3171/spi.2004.1.3.0254

15. Mobbs RJ, Chung M, Rao PJ: Bone graft substitutes for anterior lumbar interbody fusion . Orthop Surg. 2013, 5:77-85. 10.1111/os.12030

16. Cahill KS, Chi JH, Day A, Claus EB: Prevalence, complications, and hospital charges associated with use of bone-morphogenetic proteins in spinal fusion procedures. JAMA. 2009, 302:58-66. 10.1001/jama.2009.956

17. Ong KL, Villarraga ML, Lau E, Carreon LY, Kurtz SM, Glassman SD: Off-label use of bone morphogenetic proteins in the United States using administrative data. Spine. 2010, 35:1794-1800. 10.1097/BRS.0b013e3181ecf6e4

18. Cheng H, Jiang W, Phillips FM, et. al: Osteogenic activity of the fourteen types of human bone morphogenetic proteins (BMPs). J Bone Joint Surg Am. 2003, 85-A:1544-1552.

19. Mummaneni PV, Pan J, Haid RW, Rodts GE: Contribution of recombinant human bone morphogenetic protein-2 to the rapid creation of interbody fusion when used in transforaminal lumbar interbody fusion: a preliminary report. Invited submission from the Joint Section Meeting on Disorders of the Spine and Peripheral Nerves, March 2004. J Neurosurg Spine. 2004, 1:19-23. 10.3171/spi.2004.1.1.0019

20. Choudhry OJ, Christiano LD, Singh R, Golden BM, Liu JK: Bone morphogenetic protein-induced inflammatory cyst formation after lumbar fusion causing nerve root compression. J Neurosurg Spine. 2012, 16:296-301. 10.3171/2011.11.spine11629

21. Chrastil J, Low JB, Whang PG, Patel AA: Complications Associated With the Use of the Recombinant 
Human Bone Morphogenetic Proteins for Posterior Interbody Fusions of the Lumbar Spine. Spine. 2013, 38:1020-1027. 10.1097/BRS.0b013e3182982f8e

22. Lubelski D, Abdullah KG, Steinmetz MP, Alvin MD, Nowacki AS, Chakka S, Benzel EC, Mroz TE: Adverse Events With the Use of rhBMP-2 in Thoracolumbar and Lumbar Spine Fusions: A 9-Year Institutional Analysis. J Spinal Disord Tech. 2015, 28:E277-E283.

23. Mannion RJ, Nowitzke AM, Wood MJ: Promoting fusion in minimally invasive lumbar interbody stabilization with low-dose bone morphogenic protein-2--but what is the cost?. Spine J. 2011, 11:527533. 10.1016/j.spinee.2010.07.005

24. Rihn JA, Patel R, Makda J, Hong J, Anderson DG, Vaccaro AR, Hilibrand AS, Albert TJ: Complications associated with single-level transforaminal lumbar interbody fusion. Spine J. 2009, 9:623-629. 10.1016/j.spinee.2009.04.004

25. Vaidya R, Sethi A, Bartol S, Jacobson M, Coe C, Craig JG: Complications in the use of rhBMP-2 in PEEK cages for interbody spinal fusions. J Spinal Disord Tech. 2008, 21:557-562. 10.1097/BSD.0b013e31815ea897

26. Muchow RD, Hsu WK, Anderson PA: Histopathologic inflammatory response induced by recombinant bone morphogenetic protein-2 causing radiculopathy after transforaminal lumbar interbody fusion. Spine J. 2010, 10:1-6. 10.1016/j.spinee.2010.06.020

27. Mesfin A, Buchowski JM, Zebala LP, et. al: High-dose rhBMP-2 for adults: major and minor complications: a study of 502 spine cases. J Bone Joint Surg Am. 2013, 95:1546-1553. 10.2106/jbjs.1.01730

28. Chen NF, Smith ZA, Stiner E, Armin S, Sheikh H, Khoo LT: Symptomatic ectopic bone formation after off-label use of recombinant human bone morphogenetic protein-2 in transforaminal lumbar interbody fusion. J Neurosurg Spine. 2010, 12:40-46. 10.3171/2009.4.SPINE0876

29. Joseph V, Rampersaud YR: Heterotopic bone formation with the use of rhBMP2 in posterior minimal access interbody fusion: a CT analysis. Spine. 2007, 32:2885-2890. 10.1097/BRS.0b013e31815b7596

30. Owens K, Glassman SD, Howard JM, Djurasovic M, Witten JL, Carreon LY: Perioperative complications with rhBMP-2 in transforaminal lumbar interbody fusion. Eur Spine J. 2011, 20:612-617.

10.1007/s00586-010-1494-7

31. Wong DA, Kumar A, Jatana S, Ghiselli G, Wong K: Neurologic impairment from ectopic bone in the lumbar canal: a potential complication of off-label PLIF/TLIF use of bone morphogenetic protein-2 (BMP-2). Spine J. 2008, 8:1011-1018. 10.1016/j.spinee.2007.06.014

32. Carragee EJ, Hurwitz EL, Weiner BK: A critical review of recombinant human bone morphogenetic protein-2 trials in spinal surgery: emerging safety concerns and lessons learned. Spine J. 2011, 11:471491. 10.1016/j.spinee.2011.04.023

33. Chrastil J, Patel AA: Complications associated with posterior and transforaminal lumbar interbody fusion. J Am Acad Orthop Surg. 2012, 20:283-291.

34. Mindea SA, Shih P, Song JK: Recombinant human bone morphogenetic protein-2-induced radiculitis in elective minimally invasive transforaminal lumbar interbody fusions: a series review. Spine. 2009, 34:1480-1484. 10.1097/BRS.0b013e3181a396a1

35. Rihn JA, Makda J, Hong J, Patel R, Hilibrand AS, Anderson DG, Vaccaro AR, Albert TJ: The use of RhBMP2 in single-level transforaminal lumbar interbody fusion: a clinical and radiographic analysis. Eur Spine J. 2009, 18:1629-1636. 10.1007/s00586-009-1046-1

36. Rowan FE, O'Malley N, Poynton A: RhBMP-2 use in lumbar fusion surgery is associated with transient immediate post-operative leg pain. Eur Spine J. 2012, 21:1331-1337. 10.1007/s00586-011-2113-y

37. Neuman BJ, Radcliff K, Rihn J: Cauda equina syndrome after a TLIF resulting from postoperative expansion of a hydrogel dural sealant. Clin Orthop Relat Res. 2012, 470:1640-1645. 10.1007/s11999-0112071-z

38. Patel VV, Zhao L, Wong P, Pradhan BB, Bae HW, Kanim L, Delamarter RB: An in vitro and in vivo analysis of fibrin glue use to control bone morphogenetic protein diffusion and bone morphogenetic protein-stimulated bone growth. Spine J. 2006, 6:397-403. 10.1016/j.spinee.2005.11.006

39. Haid RW Jr, Branch CL Jr, Alexander JT, Burkus JK: Posterior lumbar interbody fusion using recombinant human bone morphogenetic protein type 2 with cylindrical interbody cages. Spine J. 2004, 4:527-538. 10.1016/j.spinee.2004.03.025

40. Christensen TJ, Annis P, Hohl JB, Patel AA: Neuroforaminal chondrocyte metaplasia and clustering associated with recombinant bone morphogenetic protein-2 usage in transforaminal lumbar interbody fusion. Spine J. 2014, 14:23-28. 10.1016/j.spinee.2013.11.028

41. Xu H, Tang H, Li Z: Surgical treatment of adult degenerative spondylolisthesis by instrumented transforaminal lumbar interbody fusion in the Han nationality. J Neurosurg Spine. 2009, 10:496-499. 10.3171/2009.2.spine08623

42. Than KD, Rahman SU, McKeever PE, Wang AC, La Marca F, Park P: Symptomatic calcified perineural cyst after use of bone morphogenetic protein in transforaminal lumbar interbody fusion: a case report. Spine J. 2013, 13:31-35. 10.1016/j.spinee.2013.05.020

43. Tumialán LM, Pan J, Rodts GE, Mummaneni PV: The safety and efficacy of anterior cervical discectomy and fusion with polyetheretherketone spacer and recombinant human bone morphogenetic protein-2: a review of 200 patients. J Neurosurg Spine. 2008, 8:529-535. 10.3171/SPI/2008/8/6/529 
Cureus

44. Fransen M, Neal B, Cameron ID, Crawford R, Tregonning G, Winstanley J, Norton R, HIPAID Collaborative Group: Determinants of heterotopic ossification after total hip replacement surgery . Hip Int. 2009, 19:41-46.

45. Anand N, Hamilton JF, Perri B, Miraliakbar H, Goldstein T: Cantilever TLIF with structural allograft and RhBMP2 for correction and maintenance of segmental sagittal lordosis: long-term clinical, radiographic, and functional outcome. Spine. 2006, 31:E748-E753. 10.1097/01.brs.0000240211.23617.ae 